Archimer, archive institutionnelle de l'ffremer

Vol. 56, Numbers 5-6 / December, 2006 : 445-451

http://www.ifremer.fr/docelec/

http://dx.doi.org/10.1007/s10236-005-0046-x

(C) 2006 Springer

\title{
Perspectives on present-day sea level change: a tribute to Christian le Provost
}

\author{
Alix Lombard ${ }^{1, *}$, Anny Cazenave ${ }^{1}$, Pierre Yves Le $\operatorname{Traon}^{2}$, Stephanie Guinehut ${ }^{2}$ and \\ Cécile Cabanes ${ }^{3}$
}

(1) LEGOS-CNES, 18 avenue, E. Belin, 31401 Tuolouse, cedex 9, France

(2) IFREMER, Plouzané, France

(3) JPL, Pasadena, CA, USA

*: Corresponding author : lombard@notos.cst.cnes.fr

\begin{abstract}
:
In this paper, we first discuss the controversial result of the work by Cabanes et al. (Science 294:840$842,2001)$, who suggested that the rate of past century sea level rise may have been overestimated, considering the limited and heterogeneous location of historical tide gauges and the high regional variability of thermal expansion which was supposed to dominate the observed sea level. If correct, this conclusion would have solved the problem raised by the IPCC third assessment report [Church et al, Cambridge University Press, Cambridge, pp 881, 2001], namely, the factor two difference between the 20th century observed sea level rise and the computed climatic contributions. However, recent investigations based on new ocean temperature data sets indicate that thermal expansion only explains part (about $0.4 \mathrm{~mm} / \mathrm{year}$ ) of the $1.8 \mathrm{~mm} /$ year observed sea level rise of the past few decades. In fact, the Cabanes et al.'s conclusion was incorrect due to a contamination of abnormally high ocean temperature data in the Gulf Stream area that led to an overestimate of thermal expansion in this region. In this paper, we also estimate thermal expansion over the last decade (1993-2003), using a new ocean temperature and salinity database. We compare our result with three other estimates, two being based on global gridded data sets, and one based on an approach similar to that developed here. It is found that the mean rate of thermosteric sea level rise over the past decade is $1.5 \pm 0.3$ $\mathrm{mm} /$ year, i.e. $50 \%$ of the observed $3 \mathrm{~mm} /$ year by satellite altimetry. For both time spans, past few decades and last decade, a contribution of $1.4 \mathrm{~mm} / \mathrm{year}$ is not explained by thermal expansion, thus needs to be of water mass origin. Direct estimates of land ice melt for the recent years account for about $1 \mathrm{~mm} /$ year sea level rise. Thus, at least for the last decade, we have moved closer to explaining the observed rate of sea level rise than the IPCC third assessment report.
\end{abstract}

Keywords: Sea level - Thermal expansion - Climate change - Ocean warming 


\section{Introduction}

The chapter on sea level change of the Third Assessment Report (TAR) of the IPCC published in 2001 (Church et al., 2001) compares the tide gauge-based rate of sea level rise for the $20^{\text {th }}$ century (in the range $1 .-2$. $\mathrm{mm} / \mathrm{yr}$ ) to climatic and anthropogenic contributions (thermal expansion, glaciers and ice sheets melting, change in terrestrial water storage). Acording to the TAR, thermal expansion due to ocean warming, estimated from Ocean General Circulation Models (OGCMs), contributes $0.5 \mathrm{~mm} / \mathrm{yr}$ to the global mean sea level rise. The estimated contribution arising from mountain glaciers melting is in the range 0.2 to $0.4 \mathrm{~mm} / \mathrm{yr}$. Model-based Greenland and Antarctica mass imbalance (accounting for a longterm readjustment since Last Glacial Maximum plus a climate-related response) contributes 0.2 to $0.6 \mathrm{~mm} / \mathrm{yr}$. Finally the TAR provides a contribution to sea level due to change in terrestrial water storage by human activities. The latter contribution is very uncertain, in the range of -1.1 to $+0.4 \mathrm{~mm} / \mathrm{yr}$ with a median value of $-0.35 \mathrm{~mm} / \mathrm{yr}$ (i.e., corresponding to sea level drop). The sum of these contributions ranges from -0.8 to $2.2 \mathrm{~mm} / \mathrm{yr}$, with a median value of $0.7 \mathrm{~mm} / \mathrm{yr}$. Compared to the observed $20^{\text {th }}$ century rate of sea level rise (between 1 . $\mathrm{mm} / \mathrm{yr}$ and 2. $\mathrm{mm} / \mathrm{yr}$, with a median value of $1.5 \mathrm{~mm} / \mathrm{yr}$ ), the sum of the computed contributions is only $0.7 \mathrm{~mm} / \mathrm{yr}$, i.e., only half the observed value, even though there is complete overlap between the respective uncertainties. Thus the following questions were raised by Munk (2002):

- Is sea level rise observed with tide gauges overestimated?

- Are the climatic and anthropogenic factors causing sea level rise underestimated?

- $\quad$ Are both estimates wrong?

In a paper published in 2001, Cabanes et al. suggested a solution to the 'enigma' and proposed that the rate of sea level rise observed by tide gauges could be overestimated by a factor of $\sim 2$. This suggestion led to considerable doubt and controversy in the scientific community (e.g., Miller and Douglas, 2004). We now know that it was incorrect and that the most likely answer to the enigma is the second possibility, i.e., the total value proposed in the TAR for the climatic and anthropogenic contributions likely represents a lower bound. Since the TAR publication, several new results have been made available, making the sea level problem significantly clearer, even if some old questions are not yet fully solved and new questions have been raised. In this paper, we provide a synthesis of our current understanding of present-day sea level rise and its causes. 


\section{The Cabanes et al. (2001) study}

In a paper devoted to estimating the contribution of thermal expansion to present-day sea level rise, Cabanes et al. (2001) suggested that over the short 6-year period 1993-1998, the rate of sea level rise measured by Topex/Poseidon satellite altimetry (of $\sim 2.7 \mathrm{~mm} / \mathrm{yr}$ ) was almost fully explained by thermal expansion. This conclusion resulted from the computation of the thermosteric sea level based on the newly published global ocean temperature data set by Levitus et al. (2000). Cabanes et al. (2001) further assumed that thermal expansion was the dominant contribution to sea level rise over the past few decades. Using the Levitus et al. (2000) temperature data, they computed the thermosteric sea level at the 27 historical tide gauges used by Douglas (2001) and Peltier (2001) to estimate past century sea level rise. They found that the average value of the thermosteric rate at the tide gauges was $1.3+/-0.10 \mathrm{~mm} / \mathrm{yr}$ for the period 1955-1995, a value more than 2 times larger than the global mean thermosteric rate averaged over the whole ocean (of $0.5 \pm 0.05 \mathrm{~mm} / \mathrm{yr}$; see also Antonov et al., 2002). They proposed that the rate of global sea level rise deduced from these few tide gauges could be significantly overestimated, considering the important regional variability of the thermosteric sea level trends. In effect, the heterogeneous and limited coverage of historical tide gauges does not seem able to capture this regional variability. Moreover, the historical tide gauges are preferentially located in regions where oceans experienced significant warming during the past few decades (according to the Levitus et al., 2000' data set). For that reason, Cabanes et al. (2001) suggested that averaging geographically poorly distributed tide gauges data cannot lead to a very meaningful estimate of the global average. Cabanes et al. (2001) also checked whether the computed thermosteric sea level rise correctly reproduced the observed tide gauge-derived sea level rise. They used tide gauges records from the Permanent Service for Mean Sea Level (PSMSL, Woodworth and Player, 2003) at the 27 sites. They found that the observed (i.e., tide gauge-derived) mean sea level rise over 1955-1995 amounted to $1.6+$ $0.15 \mathrm{~mm} / \mathrm{yr}$, a value not far from the mean thermosteric rate $(1.3+/-0.10 \mathrm{~mm} / \mathrm{yr})$ averaged at the 27 tide gauges sites.

\section{Recent estimates of thermal expansion for the past 50 years and last decade: global approach}

\section{1 global gridded temperature data sets}

Several new global ocean temperature data sets have been made available in the recent years, allowing the thermal expansion contribution to sea level rise to be re-estimated. In addition to 
the Levitus et al. (2000) estimate mentioned above, a Japanese group (Ishii et al., 2003) provided another global gridded temperature data set for 1950-1998. Both groups recently updated to 2005 their former data sets (Ishii et al., 2005; Levitus et al., 2005), with some corrections to the data for the recent years (see below) and additional raw data for the Levitus group. The former Ishii et al. (2003) data set consists of monthly $1^{\circ} \times 1^{\circ}$ gridded annual temperature fields given as monthly means down to 500 m from 1950 to 1998 and down to $700 \mathrm{~m}$ for the extended (1950-2003) period (Ishii et al., 2005). Details on the raw data and objective analysis scheme developed to compute global gridded temperatures can be found in Ishii et al. (2003, 2005). The Levitus et al. $(2000,2005)$ data are given as yearly $1^{\circ} \times 1^{\circ}$ gridded averages over 1950-1998/1955-2003 for the 0-500 m/0-700 m layer, and as 5-year $1^{\circ} \mathrm{x} 1^{\circ}$ gridded averages for 1947-1994/1957-1996 and the 0-3000 m layer.

Lombard et al. (2005a) used the gridded ocean temperature data set from Ishii (2003) to re estimate thermal expansion since 1950 and noticed that over the period 1950-1990, the thermosteric sea level curves based on Levitus et al. (2000) and Ishii et al. (2003) respectively agree well, while over 1990-1998 there is some discrepancy between the two curves. This discrepancy arises because, for the period 1990-1998, the two data sets are contaminated by the XBT (Expandable Bathy Thermograph) depth correction (Hanawa et al., 1995), applied twice in the former Levitus et al. (2000) data set for years 1997-1998 and not applied at all in the Ishii et al. (2003) data for years 1990-1998. This correction has a systematic effect on a large fraction of all ocean temperature data in the early 1990's, hence its application affects the global average of thermosteric sea-level for those years. The result is an overestimate/underestimate of the thermal expansion during the 1990s using the Levitus et al. (2000)/Ishii et al. (2003) data respectively. This is illustrated in Fig.1 which shows the thermosteric sea level curves based on the four sets of temperature data (Levitus et al., 2000, 2005 and Ishii et al., 2003, 2005). The temperature overestimate by Levitus et al. (2000) explains why Cabanes et al. (2001) found good agreement over 1993-1998 between Topex/Poseidon-based sea level rise and thermal expansion using the Levitus et al. (2000) data. As we will see below, there is now some consensus that thermal expansion does not exceed $50 \%-60 \%$ of the observed sea level rise for the last decade.

The updated gridded data sets from the two groups (Levitus et al., 2005, Ishii et al., 2005) now correctly account for the XBT depth correction, and in the following we will refer to these new data sets only. Figure 2 compares the thermosteric sea level curves computed using Levitus et al.'s (2005) data and Ishii et al.'s (2005) data, for 1955-2003. Both curves now agree remarkably well. The thermosteric sea level rise from the Ishii et al. (2005) data 
down to $700 \mathrm{~m}$ is $0.34+/-0.04 \mathrm{~mm} / \mathrm{yr}$ over $1955-2003$. Over the same period and same depth range, the value based on the Levitus et al. (2005) data (see Antonov et al., 2005) is $0.36+/-$ $0.04 \mathrm{~mm} / \mathrm{yr}$. For the 0-3000 $\mathrm{m}$ depth layer, thermal expansion for 1957-1996 is $0.45+/-0.05$ $\mathrm{mm} / \mathrm{yr}$ (Antonov et al., 2005). For the last decade (1993-2003) and 0-700m depth layer, the two above data sets give the following values: $1.2+/-0.2 \mathrm{~mm} / \mathrm{yr}$ (Ishii et al., 2005) and 1.3 +/- $0.2 \mathrm{~mm} / \mathrm{yr}$ (Antonov et al., 2005).

For the period 1993-2003, there are two other estimates of thermal expansion (Willis et al., 2004) and this study. The Willis et al.' study combines satellite altimetry and in situ hydrographic profiles down to $750 \mathrm{~m}$. They compute a rate of thermosteric sea level rise of $1.6+/-0.3 \mathrm{~mm} / \mathrm{yr}$ for 1993-2003. Another estimate also based on hydrographic profiles is provided in the present study and presented in the next section.

\subsection{Thermal expansion estimate for 1993-2003 using the CLS ARMOR data base}

The ARMOR (Multivariate Analysis of the MERCATOR Observations) reanalysis is a product of CLS-Space Oceanography Division in cooperation with the MERCATOR project (Guinehut et al., 2004). It consists of high resolution and global satellite data (sea surface temperature - SST-, and altimetry sea level anomalies - SLA), combined with accurate but sparse in-situ hydrographic profiles (temperature and salinity - T/S-). These data were used to construct instantaneous 3-D global temperature and salinity fields, down to $700 \mathrm{~m}$, with high temporal and spatial resolution. The first step consisted of a vertical projection of satellite data (SST and SLA) through a multiple linear regression method to obtain synthetic T/S profiles. The second step consisted of combining these synthetic profiles with in-situ hydrographic profiles using an optimal interpolation method to estimate the new profiles. More details on the method can be found in Guinehut et al. (2004).

The SLA data are weekly, $1 / 3^{\circ} \times 1 / 3^{\circ}$ mercator gridded sea surface heights from Topex/Poseidon, Jason-1, ERS1/2, ENVISAT and GFO satellites. The SST fields from NCEP/NOAA are based on satellite observations (AVHRR) and are provided weekly on $1^{\circ} \times 1^{\circ}$ grids. Finally in-situ hydrographic profiles are compiled from CORIOLIS and ENACT data centers : about 900.000 temperature profiles and 130.000 salinity profiles valid until $700 \mathrm{~m}$ depth are available from different sources (profiling floats from the ARGO project, moored buoys from the TAO/PIRATA array, XBT, CTD, etc.). The ARMOR reanalysis consists of 3-D gridded temperature and salinity fields, given every 7 days from 1993 to 2003, on a $1 / 3^{\circ} \times 1 / 3^{\circ}$ mercator grid, and the upper $700 \mathrm{~m}$ at Levitus standard depth levels. Using 
these T/S grids, we have computed the corresponding steric sea level at each grid point and each time step. However, as we do not need such a high spatial and temporal resolution here, we also computed monthly means of the steric sea level on a $1^{\circ} \mathrm{x} 1^{\circ}$ global grid. Additionally, we applied a 12-month moving average over the 10-year period in order to remove the annual signal. Note that ARMOR is the only data set providing 3-D salinity fields coherent with the corresponding temperature fields. This allows us to compute a not only thermosteric (due to temperature only) but steric (due to temperature and salinity) sea level fields.

Figure 3 compares the near-global $\left(60^{\circ} \mathrm{S}-60^{\circ} \mathrm{N}\right)$ averaged steric sea level variations over 1993-2003 from the ARMOR T/S fields with the same curves based on other studies (from Willis et al., 2004, Antonov et al., 2005 and Ishii et al., 2005). The observed (i.e. Topex/Poseidon-based) sea level curve is also shown. The ARMOR and Willis et al. (2004) curves agree well in terms of decadal trends (of $1.8 \pm 0.2 \mathrm{~mm} / \mathrm{yr}$ for ARMOR and $1.6 \pm 0.3$ mm/yr for Willis et al.’s data), whereas the Ishii et al. (2005)'s and Antonov et al. (2005)' thermosteric curves are slightly below $(1.2 \pm 0.2 \mathrm{~mm} / \mathrm{yr}$ for Ishii et al.' data and $1.3 \pm 0.2$ $\mathrm{mm} / \mathrm{yr}$ for Antonov et al.' data). Figure 3 also shows the residual curves (i.e. Topex/Poseidon-based sea level curve minus thermal expansion) for the four cases considered above. We note that the residual curves display interannual variability, with a trend superimposed. All residual curves - except for ARMOR's curve - show a large positive anomaly in late 1997- early 1998, as does the observed (from Topex/Poseidon) sea level curve. This positive anomaly is likely related to direct and indirect effects of the 1997-1998 ENSO event (e.g., Cazenave and Nerem, 2004). Ngo-Duc et al. (2005a), for example, showed that the contribution of land waters to sea level was larger in 1997 than in 1998, an indirect effect of the 1997-1998 ENSO on the global water cycle. However, the ARMOR steric sea level curve closely follows the observed curve, suggesting that the positive anomaly seen in 1997-1998 in the Topex/Poseidon sea level has rather a thermal origin Table 1 gathers the various estimates of thermal expansion rates discussed above for 1993-2003 and 1955-2003.

Figure 4 presents the geographical distribution of the rates of sea level change over 1993-2003 based on Topex/Poseidon (upper panel) and ARMOR thermal expansion (lower panel). As noticed in previous studies (Cabanes et al., 2001, Cazenave and Nerem, 2004, Willis et al., 2004 and Lombard et al., 2005a), the regional variability seen in the observed rates of sea level change is dominated by thermal expansion regional variability. We note that the ARMOR thermal expansion agrees well with the observed patterns (correlation of 0.85), in particular in the southern oceans (correlation of 0.80), which was not the case with the 
Levitus et al.'s (2000, 2005) and Ishii et al.’s (2003, 2005) gridded data sets (see Lombard et al., 2005a for a discussion).

If we simply consider the arithmetic mean value of the above four thermal expansion trends, we get a value of $1.5 \mathrm{~mm} / \mathrm{yr}$. We assume that the uncertainty associated with this thermosteric rate is on the order of $0.3 \mathrm{~mm} / \mathrm{yr}$, a value which accounts for the dispersion of the estimates and formal errors. This thermal expansion contribution $(1.5+/-0.3 \mathrm{~mm} / \mathrm{yr})$ explains only part (50\%) of the observed rate of sea level rise computed with Topex/Poseidon altimetry over 1993-2003 (of 3.0 +/- 0.4 mm/yr ; Cazenave and Nerem, 2004). Over that period, there is a large residual, of $1.5 \mathrm{~mm} / \mathrm{yr}$, of non thermal origin. This new result disagrees with that of Cabanes et al. (2001) which compared, over 1993-1998, the altimetry-based sea level rise with thermal expansion computed with the former Levitus et al. (2000) data set (see above). Over the longer period (1955-2003), the rate of thermosteric sea level rise is 0.4 $\mathrm{mm} / \mathrm{yr}$ (0-3000 m depth range, Antonov et al., 2005), i.e., 22\% only of the observed rate of rise by the tide gauges (of $1.8 \mathrm{~mm} / \mathrm{yr}$; e.g., Church et al., 2004, Holgate and Woodworth, 2004). It thus appears that for both periods (last decade and last 50 years), there is an ocean mass contribution of the order of $1.4 \mathrm{~mm} / \mathrm{yr}$.

\section{New estimates of thermal expansion at historical tide gauges sites; inference on ocean mass contribution to sea level rise}

Miller and Douglas (2004) analysed raw hydrographic data available for the past decades and re estimated the thermosteric sea level at a few tide gauges sites located in the northern Pacific and northern Atlantic. They found that in three regions (northeast Atlantic, northeast Pacific and central Pacific -Hawaii-) the rate of thermosteric sea level rise did not exceed $0.5 \mathrm{~mm} / \mathrm{yr}$ since 1920, thus this was much too low to explain the observed (i.e., tide gauge-based) sea level rise. They concluded that the Cabanes et al. (2001) result was incorrect. They further showed that the interpolated ocean temperature data from the Levitus et al. (2000) data set were in error in the Gulf Stream region (offshore of the northeast coast of the U.S.), leading to an overestimated thermosteric sea level rise in this region. Miller and Douglas concluded that since the Cabanes et al. (2001) comparison was dominated by tide gauges sites in this region, their result was contaminated by the abnormally high ocean temperature of the Gulf Stream area. They came to the conclusion that the thermosteric contribution accounts for only a small fraction to the $20^{\text {th }}$ century sea level rise and that the dominant contribution is the addition of water to the ocean. 
Recently Lombard et al. (2005b) re computed the thermosteric contribution at historical tide gauges using the Ishii et al. (2003) data set. They considered almost the same tide gauges sites as in Cabanes et al. (2001) and applied exactly the same method of interpolation (while Miller and Douglas, 2004, averaged the hydrographic data over very wide -several thousands km- areas, Cabanes et al., 2001 and Lombard et al., 2005b interpolated the temperature data inside a variable radius around the tide gauge, of dimension ranging from $100 \mathrm{~km}$ to $450 \mathrm{~km}$ ). Lombard et al. (2005b) found that over 1950-1998 the average thermosteric sea level rise at the 27 historical tide gauge sites is $0.3+/-0.16 \mathrm{~mm} / \mathrm{yr}$, while the average observed sea level rise derived from the tide gauges observations is $1.84+/-0.40$ $\mathrm{mm} / \mathrm{yr}$, for the same time span. Lombard et al. (2005b) compared these results with the old and new Levitus data sets and found that there is good agreement between Ishii-based and Levitus-based thermosteric sea level at 17 tide gauges sites, but not at the 9 tide gauge sites located along the northeast coast of the US, north of $37^{\circ} \mathrm{N}$, where use of the Levitus data leads to an overestimate of the rate of thermosteric sea level rise. Ignoring these sites provides an estimate of thermal expansion of around $0.4 \mathrm{~mm} / \mathrm{yr}$ over the past 50 years, whatever the ocean temperature data set considered, in agreement with Miller and Douglas' result. These two studies (Miller and Douglas, 2004 and Lombard et al. 2005b) indicate that the conclusions of Cabanes et al. (2001) were incorrect. They also indirectly show that a large fraction $(\sim 1.4$ $\mathrm{mm} / \mathrm{yr}$ ) of the past few decades of sea level rise is caused by the addition of water mass.

The ocean mass contribution arises from several sources: land water storage, mountain glaciers melting and ice sheets mass loss. New direct estimates are now available for the ice sheets and glaciers contributions to sea level rise. Most recent estimates of glaciers/ice caps melting, Greenland and Antarctica mass loss over the past decade lead to $\sim 0.75 \mathrm{~mm} / \mathrm{yr}, ~ 0.20$ $\mathrm{mm} / \mathrm{yr}$ and $\sim 0.10 \mathrm{~mm} / \mathrm{yr}$ respectively (Arendt et al., 2002; Rignot et al., 2003, 2004; Thomas et al., 2004; Duyrgerov and Meier, 2005; Krabill et al., 2005); These results suggest a current total land ice contribution of about $1.05 \mathrm{~mm} / \mathrm{yr}$ for the recent years.

Another potential contribution may arise from change in continental water storage. This effect is still not yet well known because of lack of in situ observations at the global scale. Recently, model-based estimates for the land water contribution to sea level change have been published (Milly et al., 2003; Ngo-Duc et al., 2005b). Milly et al. (2003) used the Land Dynamics -LaD- global land surface model to estimate the contribution to sea level rise from land waters over 1981-1998. They found only a very small trend ( $0.12 \mathrm{~mm} / \mathrm{yr})$ over the 18-year period but significant interannual variability. More recently, Ngo-Duc et al. (2005b) reached the same conclusion from a 50-year run of the ORCHIDEE global land surface 
model. Over 1950-2000, the latter study showed no long-term contribution to sea level rise. On the other hand, large interannual/decadal fluctuations of a few mm amplitude are reported. Ngo-Duc et al. (2005) also noticed that the decadal variability in the land water contribution to sea level change is negatively correlated to change in ocean heat content (hence thermal expansion), leading to partial compensation between these two effects.

Finally the anthropogenic contribution due to change in land water storage by human activities is supposed to be small (around zero) (Sahagian, personal communication, 2005).

\section{Conclusion}

In this paper we have clarified the controversial result of Cabanes et al. (2001) suggesting that: (1) thermal expansion almost explains the rate of sea level rise observed by satellite altimetry in the recent years, and (2) tide gauge-based sea level rise over the past 50 years may have been overestimated. The second result, if true, would have solved the 'sea level enigma', i.e., the factor of 2 difference between observed sea level rise and climatic/anthropogenic factors, as reported by Church et al. (2001) in the IPCC third assessment report. As explained in the present paper, the Cabanes et al.'s conclusion was based on an ocean temperature data base which overestimated temperatures during the 1990s and contained anomalous high temperatures in the Gulf Stream region, leading to incorrect results. We report new thermal expansion estimates for past 50 years and the 1990s. For the latter period, we also present new thermal expansion results obtained with the ARMOR hydrographic data base. There is now a consensus that for the past 50 years, thermal expansion only explains 25\% of the observed sea level rise while for the period 1993-2003, it accounts for about 50\%. For both time spans, there is a non thermal residual, of $1.4 \mathrm{~mm} / \mathrm{yr}$, of water mass origin. Recent published estimates of land ice melt account for a significant fraction of this non thermal contribution.

\section{Acknowledgment}

We would like to dedicate this paper to Christian Le Provost. Christian Le Provost co-directed with one of us (Anny Cazenave) the PhD thesis of Cécile Cabanes . The results of Cabanes et al. (2001), shared by all three of us (Christian Le Provost, Cécile Cabanes and Anny Cazenave) when obtained, generated intense and very interesting discussions among us. Based on locally inaccurate ocean temperature data, these conclusions led to numerous comments and controversy in the scientific community. However it raised an important issue 
in sea level studies and subsequently generated several important new results. It also helped in resolving old issues about tide gauges. Cécile Cabanes and Anny Cazenave much appreciated working with Christian Le Provost on that topic.

\section{References}

Arendt, A.A., K.A. Echelmeyer, W.D. Harrison, C.S. Lingle, and V.B. Valentine, Rapid wastage of Alaska glaciers and their contribution to rising sea level, Science, 297, 382386, 2002.

Antonov, J.I., S. Levitus, and T. Boyer, Steric sea level variations during 1957-1994: Importance of salinity, J. Geophys. Res., 107(C12), 8013, doi:10.1029/2001JC000964, 2002.

Antonov, J.I., S. Levitus, and T.P. Boyer, Steric variability of the world ocean, 1955-2003, Geophysical Research Letters, 32(12), L12602, doi:10.1029/2005GL023112, 2005.

Cabanes, C., A. Cazenave, and C. LeProvost, Sea level rise during past 40 years determined from satellite and in situ observations, Science, 294, 840-842, 2001.

Cazenave A. and R.S. Nerem, Present-day sea level change: observations and causes, Review of Geophysics, 42, RG3001, doi : 8755-1209/04/2003RG000139, 2004.

Church, J.A., Gregory, J.M., Huybrechts, P., Kuhn, M., Lambeck, K., Nhuan, M.T., Qin, D. \& Woodworth, P.L., Changes in sea level. In Climate Change 2001: The Scientific Basis. Contribution of Working Group I to the Third Assessment Report of the Intergovernmental Panel on Climate Change, J.T. Houghton, Y. Ding, D.J. Griggs, M. Noguer, P.J. van der Linden, X. Dai, K. Maskell and C.A. Johnson, eds. Cambridge University Press, Cambridge, 881pp, 2001.

Church, J.A., N.J. White, R. Coleman, K. Lambeck, and J.X. Mitrovica, Estimates of the regional distribution of sea-level rise over the 1950 to 2000 period. Journal of Climate, 17 (13), 2609-2625, 2004.

Douglas, B.C., Sea level change in the era of the recording tide gauge, in Sea level rise, History and consequences, edited by B.C. Douglas, M.S. Kearney, and S.P. Leatherman, pp. 37-64, Academic Press, San Diego, 2001.

Dyurgerov, M. and M.F. Meier, Glaciers and Changing Earth System: a 2004 snapshot, INSTAAR, Boulder, 2005.

Guinehut, S., P.Y. Le Traon, G. Larnicol and S. Philipps. Combining Argo and remotesensing data to estimate the ocean three-dimensional temperature fields - a first approach based on simulated observations. J. Mar. Sys., 46, 85-98, 2004.

Hanawa, K., P. Raul, R. Bailey, A. Sy, M. Szabados, A new depth-time equation for Sippican or TSK T-7, T-6, and T-4 expendable bathy thermographs (XBTs), Deep-Sea Research Part I, 42, 1423-1451, 1995. 
Holgate, S.J. and Woodworth, P.L. 2004 Evidence for enhanced coastal sea level rise during the 1990s. Geophys. Res. Lett., 31, L07305, doi:10.1029/2004GL019626.

Ishii, M., M. Kimoto, and M. Kachi, Historical ocean subsurface temperature analysis with error estimates, Monthly Weather Rev., 131,51-73, 2003.

Ishii, M., M. Kimoto, K. Sakamoto and S.I. Iwasaki, Steric sea level changes estimated from historical ocean subsurface temperature and salinity analyses, J. Oceanography, submitted, 2005.

Krabill, W., E. Hanna, P. Huybrechts, W. Abdalati, J. Cappelen, B. Csatho, E. Frederick, S. Manizade, C. Martin, J. Sonntag, R. Swift, R. Thomas, and J. Yungel, Greenland Ice Sheet: Increased coastal thinning. Geophys. Res. Lett. , 31, L24402, doi:10.1029/2004GL021533, 2005.

Levitus, S., J.I. Antonov, T.P. Boyer, and C. Stephens, Warming of the world ocean, Science, 287, 2225-2229, 2000.

Levitus S., J.I. Antonov and T.P. Boyer, Warming of the World Ocean, 1955-2003, Geophys. Res. Lett.,32, L02604, doi:10.1029/2004GL021592, 2005.

Lombard A., Cazenave A, Le Traon P.Y. and Ishii M., Contribution of thermal expansion to present-day sea level change revisited, Global and Planetary Change, 47, 1-16, 2005 a.

Lombard, A., A. Cazenave, K. DoMinh, C. Cabanes, and R.S. Nerem. Thermosteric sea level rise for the past 50 years ; comparison with tide gauges and inference on water mass contribution, Global and Planetary Change, 48, 303-312, 2005b.

Miller, L., and B.C. Douglas, Mass and Volume Contributions to 20th Century Global Sea Level Rise, Nature, 428, 406-408, 2004.

Milly, P.C.D., A. Cazenave, and M.C. Gennero, Contribution of climate-driven change in continental water storage to recent sea-level rise, Proc. Nat. Acad. Sci., 100 (23), 13158-13161, 2003.

Munk, W., Twentieth century sea level : An enigma, Proc. Natl. Acad. Sci. U.S.A., 99(10), 6550-6555, 2002.

Ngo-Duc T., Laval K., Polcher Y and Cazenave A., Analyses of the contribution of continental water to sea level variations during the 1997-1998 ENSO event; Comparison between the AMIP simulations and the Topex/Poseidon satellite data., J. Geophys. Res., 110, D09103, doi:10.1029/2004JDO04940, 2005a.

Ngo-Duc T., Laval K., Polcher Y., Lombard A. and Cazenave A., Effects of land water storage on the global mean sea level over the last half century, Geophys. Res. Lett., Vol.32, L09704, doi:10.1029/2005GL022719, 2005b. 
Peltier, W.R., Global glacial isostatic adjustment and modern instrumental records of relative sea level history, in Sea level rise, History and consequences, edited by B.C. Douglas, M.S. Kearney, and S.P. Leatherman, pp. 65-95, Academic Press, San Diego, 2001.

Rignot, E., A. Rivera, and G. Casassa, Contribution of the Patagonia Icefields of South America to Sea Level Rise, Science, 302, 434-437, 2003.

Rignot, E., G. Casassa, P. Gogineni, W. Krabill, A. Rivera, and R. Thomas, Accelerated ice discharge from the Antarctic peninsula following the collapse of Larsen B ice shelf, Geophys. Res. Lett., 31, L18401, doi:10.1029/2004GL020697, 2004.

Thomas R., E. Rignot, G. Casassa, P. Kanagaratnam, C. Acuna, T. Akins, H. Brecher, E. Frederick, P. Gogineni, W. Krabill, S. Manizade, H. Ramamoorthy, A. Rivera, R. Russell, J. Sonntag, R. Swift, J. Yungel and J. Zwally, Accelerated Sea Level Rise from West Antarctica, Science, 306,255-258, 2004.

Willis, J.K., D. Roemmich, and B. Cornuelle, Interannual variability in upper-ocean heat content , temperature and thermosteric expansion on global scales, J. Geophys. Res., 109, C12036, doi:10.1029/2003JC002260, 2004.

Woodworth, P.L. and R. Player, The Permanent Service for Mean Sea Level: an update to the $21^{\text {st }}$ century. J. Coastal. Res., 19, 287-295, 2003. 
Table 1: Global $\left(60^{\circ} \mathrm{S}-60^{\circ} \mathrm{N}\right)$ mean thermal expansion estimates $(0-700 \mathrm{~m}$ layer $)$ for the past 50 years and last decade

\begin{tabular}{|c|c|c|}
\hline Period & Rate of steric sea level (mm/yr) & Source \\
\hline $1955-2003$ & $0.34+/-0.04$ & Ishii et al. (2005) \\
\hline $1955-2003$ & $0.36+/-0.04$ & Antonov et al. (2005) \\
\hline $1993-2003$ & $1.2+/-0.2$ & Ishii et al. (2005) \\
\hline $1993-2003$ & $1.3+/-0.2$ & Antonov et al. (2005) \\
\hline $1993-2003$ & $1.6+/-0.3$ & Willis et al. (2004) \\
\hline $1993-2003$ & $1.8+/-0.2$ & This study (ARMOR) \\
\hline
\end{tabular}


Figure 1 : Globally-averaged thermosteric sea level over 1990-2003 from 4 sources (Levitus et al., 2000, 2005, Ishii et al., 2003, 2005). Dashed curves correspond to the former data sets affected by XBT depth correction problems (see text) (Levitus et al.,2000 in black, and Ishii et al., 2003 in red). Solid curves correspond to the corrected sets (Levitus et al. , 2005 in black, and Ishii et al., 2005 in red). The black and red curves have been artificially shifted by $15 \mathrm{~mm}$.

GLOBAL MEAN THERMOSTERIC SEA LEVEL

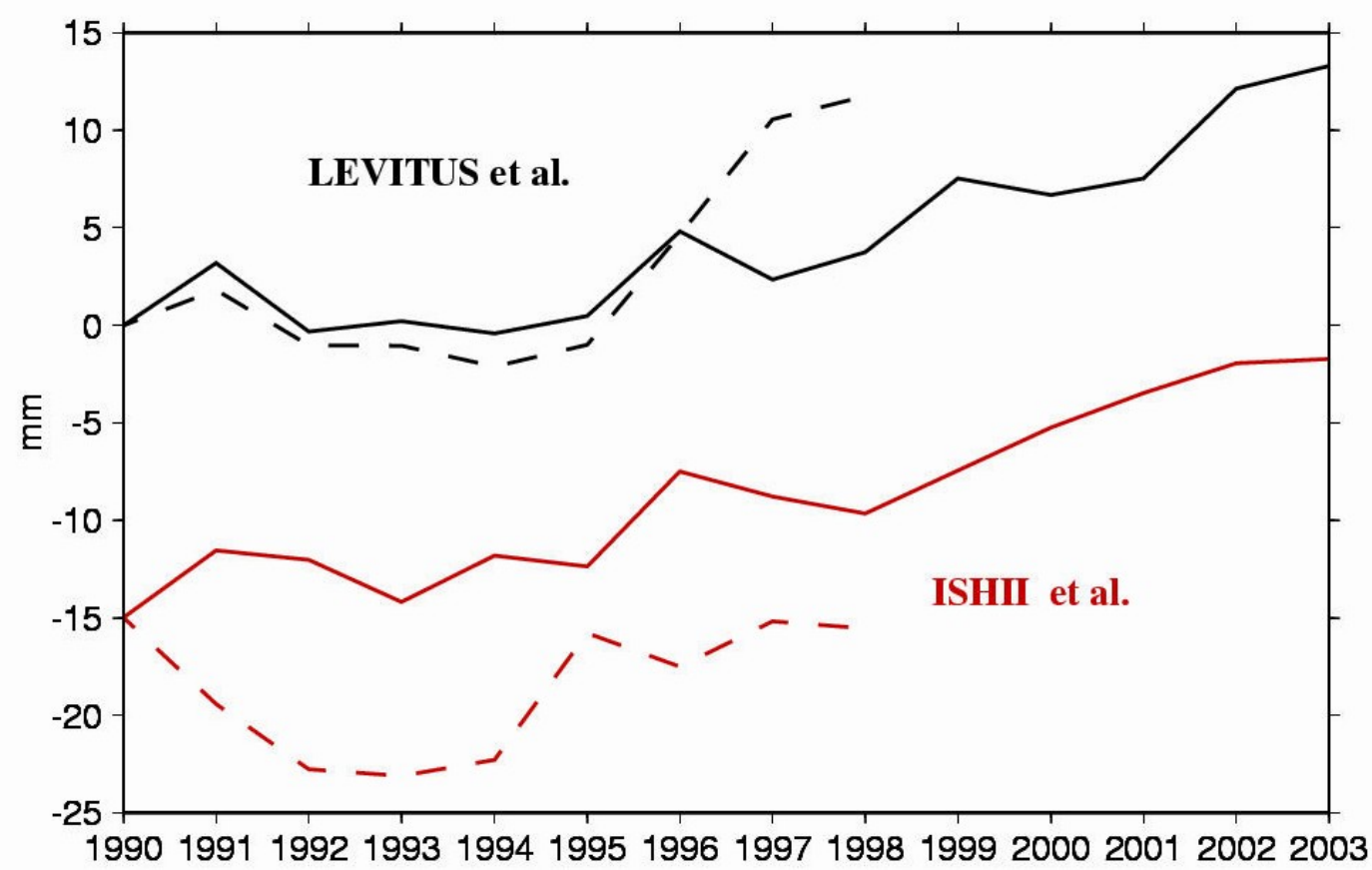


Figure 2: Thermosteric sea level curves based on Ishii et al. (2005) (red) and Levitus et al. (2005) (black) yearly-mean ocean temperature data (0-700 m layer) over 1950-2003.

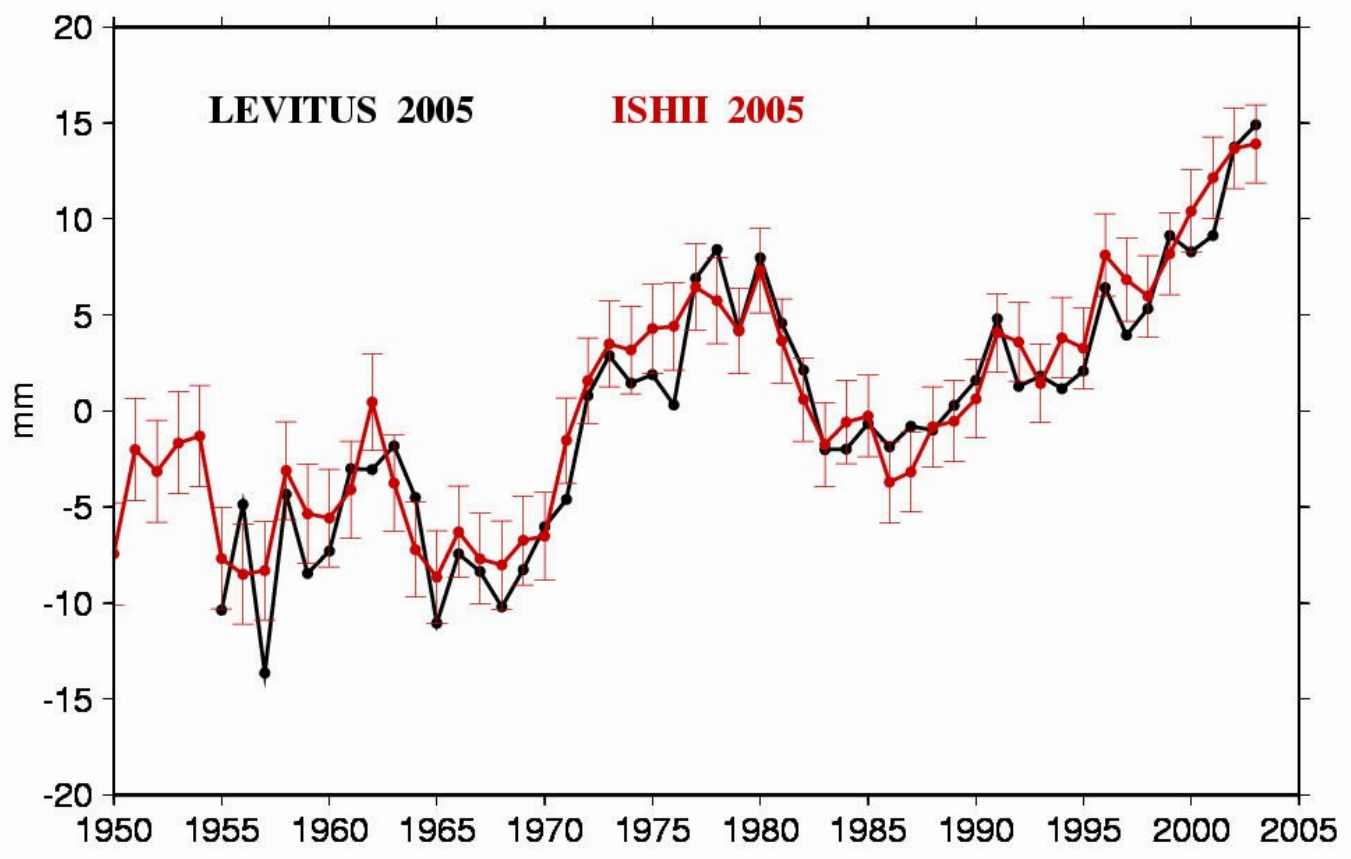


Figure 3 : Thermosteric contributions to global mean sea level rise from ARMOR data (blue), Willis et al. (2004) data (green), Levitus et al. (2005) data (red), and Ishii et al. (2005) data (purple). Global mean sea level observed by Topex/Poseidon is also shown (black curve). Residual sea level curves (Topex/Poseidon minus thermosteric, using respectively ARMOR, Willis et al., 2004, Levitus et al., 2005 and Ishii et al., 2005 temperature data) are represented as dashed curves (same colours as for the corresponding thermosteric curves)

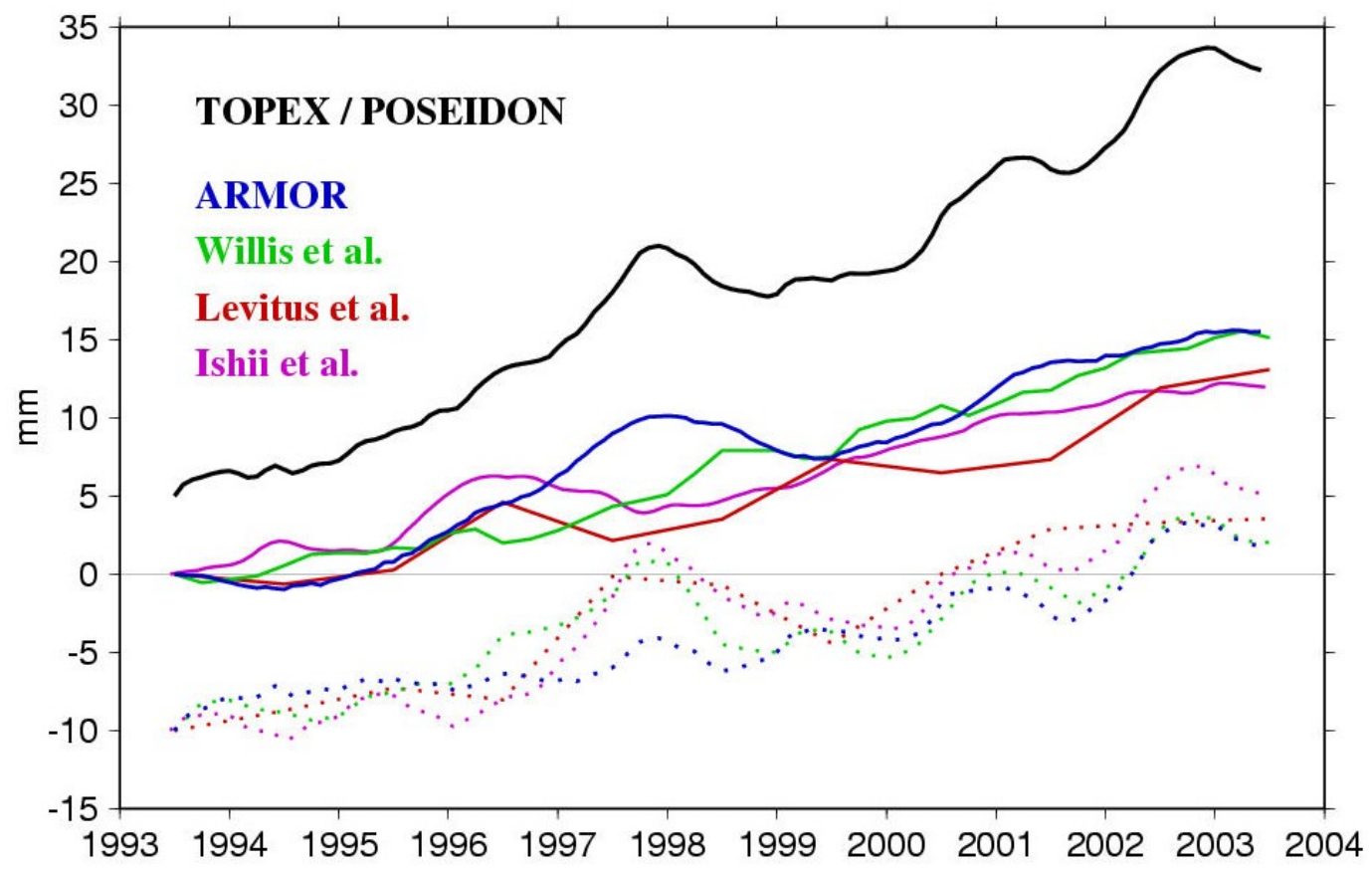


Figure 4 : Geographical distribution of rates of sea level change over 1993-2003. Upper panel : steric rates from ARMOR; Lower panel : observed rates from Topex/Poseidon.
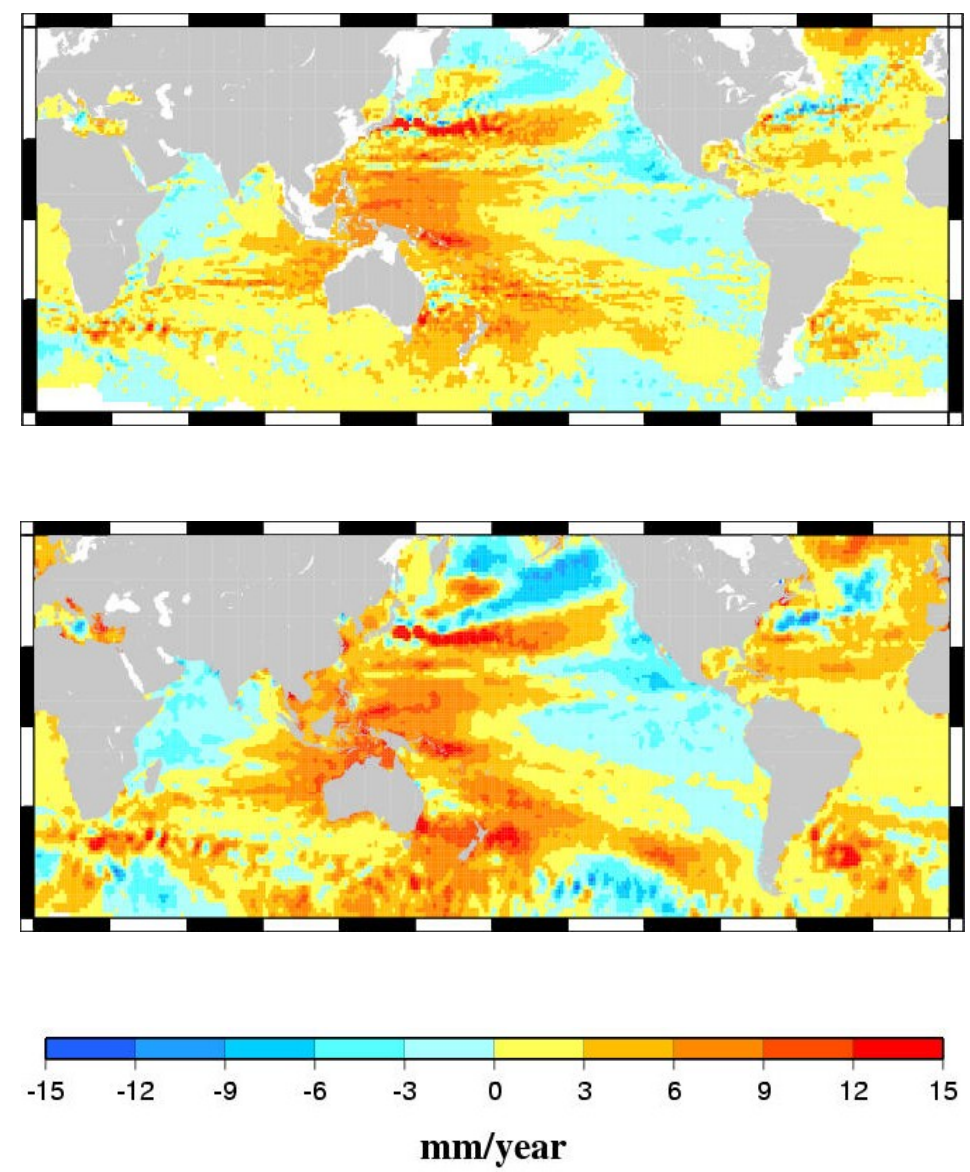